\title{
Pneumolabyrinth secondary to temporal bone fracture: a case report and review of the literature
}

This article was published in the following Dove Press journal:

International Medical Case Reports Journal

II September 2014

Number of times this article has been viewed

\author{
Andrea Bacciu' \\ Vincenzo Vincenti' \\ Sampath Chandra Prasad' \\ Daniela Tonni ${ }^{\prime}$ \\ Elisa Ventura ${ }^{2}$ \\ Salvatore Bacciu' \\ Enrico Pasanisi \\ 'Department of Clinical and \\ Experimental Medicine, Unit \\ of Audiology and Paediatric \\ Otolaryngology, ${ }^{2}$ Department \\ of Neuroradiology, University \\ Hospital of Parma, Parma, Italy
}

\begin{abstract}
Pneumolabyrinth following temporal bone fracture is an extremely rare condition. It results from air entering the inner ear when a communication between the air-filled middle ear spaces and inner ear is established. The imaging modality of choice for pneumolabyrinth is high-resolution computed tomography of the temporal bone. Treatment options include conservative management (bed rest, antibiotics, corticosteroids) or surgery (exploratory tympanotomy). We present the case of a 31-year-old female who had pneumolabyrinth secondary to a temporal bone fracture. The patient was treated surgically and made a full clinical recovery.
\end{abstract}

Keywords: pneumolabyrinth, temporal bone fractures, head trauma

\section{Introduction}

Pneumolabyrinth is a rare condition defined as the presence of air within the cochlea, vestibule, or semicircular canals, and represents radiological proof of a perilymphatic fistula. ${ }^{1}$ A perilymphatic fistula is an abnormal communication between the air-filled middle ear spaces and the inner ear that allows escape of perilymph fluid. ${ }^{1,2}$

Pneumolabyrinth secondary to temporal bone fracture is exceedingly rare, and to our knowledge, only 14 previous cases have been reported., ${ }^{1,3-11}$ The first radiological description of pneumolabyrinth was in 1984 by Mafee et al. ${ }^{12}$ Four years later, Nurre et $\mathrm{al}^{5}$ first described pneumolabyrinth occurring as a result of a temporal bone fracture.

Accepted causes of pneumolabyrinth are temporal bone fractures, barotraumatic pressure changes, and prior otological surgery. A pneumolabyrinth can be classified as follows: vestibular pneumolabyrinth, when the air bubbles are limited to the vestibule and/or the semicircular canals; cochlear pneumolabyrinth, when the air bubbles are limited to the cochlea; and combined pneumolabyrinth, when the air bubbles are found in both the vestibular organs and the cochlea. Patients may present with hearing loss, tinnitus, aural fullness and disabling vestibular symptoms. The imaging modality of choice for pneumolabyrinth is high-resolution computed tomography (CT) scan of the temporal bones. Management of pneumolabyrinth is still controversial, and could be conservative or surgical. We report the case of a 31-year-old female with a radiologically confirmed pneumolabyrinth secondary to head trauma following a car accident. We also present a further review of the literature.
Correspondence: Andrea Bacciu Department of Clinical and Experimental Medicine, Otolaryngology Unit, University Hospital of Parma,

Via Gramsci I4, 43100 Parma, Italy

Tel +3952I 703205

Email andreabacciu@yahoo.it 


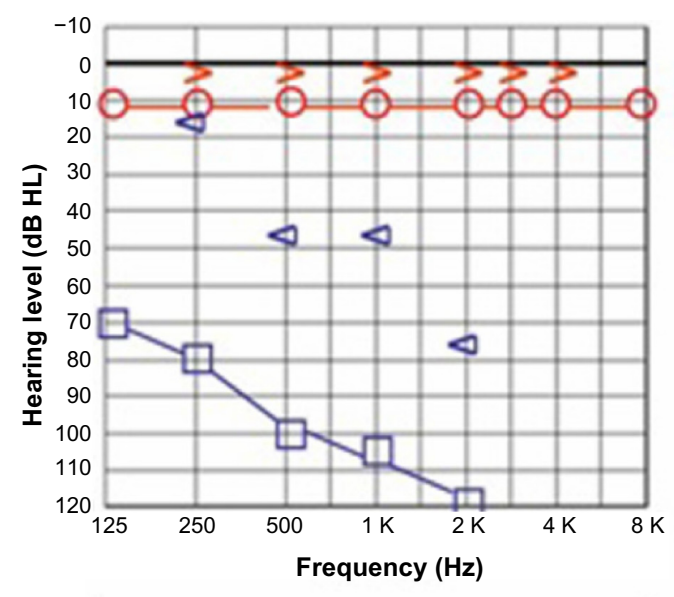

Preoperative audiogram

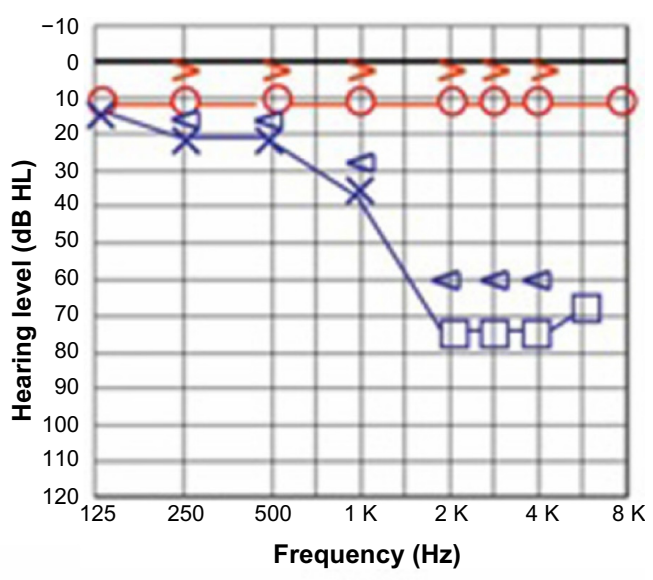

Postoperative audiogram

Figure I Preoperative pure tone audiogram showing a left-sided mixed hearing loss. Postoperative pure tone audiogram showing marked improvement, especially in the lower frequencies.

\section{Case report}

Informed consent from the patient and ethical approval was obtained for this study. A 31-year-old female who was sitting in the front passenger seat of a car without fastening her safety belt was admitted to the emergency room having been involved in a road traffic accident. Clinical and neurosurgical evaluation showed no evidence of intracranial injuries or systemic complications. CT scanning showed no evidence of intracranial complications. The patient was then referred to our department. On admission, the patient complained of left-sided hearing loss, bleeding from the ear, and severe vertigo. Otoscopic examination revealed

Table I Review of the literature

\begin{tabular}{|c|c|c|c|c|c|c|c|}
\hline Reference & Age (years) & Sex & $\begin{array}{l}\text { Type of } \\
\text { fracture }\end{array}$ & $\begin{array}{l}\text { Site of } \\
\text { pneumolabyrinth }\end{array}$ & $\begin{array}{l}\text { Site of } \\
\text { fistula }\end{array}$ & Symptoms and signs & $\begin{array}{l}\text { Preoperative } \\
\text { PTA AC (dB) }\end{array}$ \\
\hline Lipkin et $\mathrm{al}^{3}$ & 26 & $M$ & Longitudinal & Vestibule & OW, RW & $\begin{array}{l}\mathrm{HL} \text {, vertigo, tinnitus, } \\
\text { headache }\end{array}$ & 70 \\
\hline Yanagihara et $\mathrm{al}^{4}$ & 17 & $M$ & Longitudinal & NA & RW & $\mathrm{HL}$, vertigo, tinnitus & 96 \\
\hline Nurre et $\mathrm{al}^{5}$ & 57 & $M$ & Transverse & Vestibule & NA & $\mathrm{HL}$, vertigo, tinnitus, $\mathrm{HT}$ & NA \\
\hline Weissman et al ${ }^{6}$ & 25 & M & Transverse & $\begin{array}{l}\text { Vestibule, cochlea, } \\
\text { common crus }\end{array}$ & NA & $\mathrm{HL}$ & NA \\
\hline \multirow[t]{3}{*}{ Lyos et $\mathrm{al}^{7}$} & 20 & $M$ & Transverse & Vestibule & RW & $\mathrm{HL}$, vertigo & 61 \\
\hline & 20 & $M$ & Transverse & Vestibule & OW, RW & $\mathrm{HL}$, imbalance & 89 \\
\hline & 26 & $M$ & Transverse & Vestibule & ow & $\begin{array}{l}\text { HL, vertigo, tinnitus, } \\
\text { headache, HT }\end{array}$ & 84 \\
\hline Gross et a $\left.\right|^{8}$ & 2 & M & $\begin{array}{l}\text { Longitudinal } \\
\text { and transverse }\end{array}$ & Vestibule & NA & HL, EAC lacerations, HT & NA \\
\hline Woodson et al ${ }^{9}$ & 85 & $M$ & Transverse & Vestibule & NA & HL, HT & NA \\
\hline de Negreiros et al ${ }^{10}$ & 31 & M & Transverse & Vestibule & NA & $\begin{array}{l}\mathrm{HL} \text {, vertigo, tinnitus, } \\
\text { EAC lacerations, HT }\end{array}$ & NA \\
\hline \multirow[t]{3}{*}{ Prisman et al ${ }^{\prime}$} & 13 & M & $\begin{array}{l}\text { Complex TB } \\
\text { fracture }\end{array}$ & $\begin{array}{l}\text { Vestibule, cochlea, } \\
\text { PSCC }\end{array}$ & NA & HL, vertigo, nystagmus & 110 \\
\hline & 12 & M & Transverse & Vestibule, cochlea & NA & $\begin{array}{l}\text { HL, vertigo, seizure, } \\
\text { bloody otorrhea }\end{array}$ & NA \\
\hline & 4 & $M$ & Transverse & Vestibule, PSCC & NA & HL, vertigo, nystagmus & 70 \\
\hline Adil et al" & 7 & $M$ & Transverse & Vestibule & OW, RW & HL, vertigo, nystagmus & NA \\
\hline Present case & 31 & $\mathrm{~F}$ & Longitudinal & Vestibule, cochlea & ow & $\mathrm{HL}$, vertigo & 95 \\
\hline
\end{tabular}

Abbreviations: M, male; F, female; PTA, pure tone average; AC, air conduction; BC, bone conduction; OW, oval window; RW, round window; IAC, internal auditory canal; PSCC, posterior semicircular canal; TB, temporal bone; NA, not available; HL, hearing loss; SNHL, sensorineural hearing loss; EAC, external auditory canal; HT, hemotympanum. 


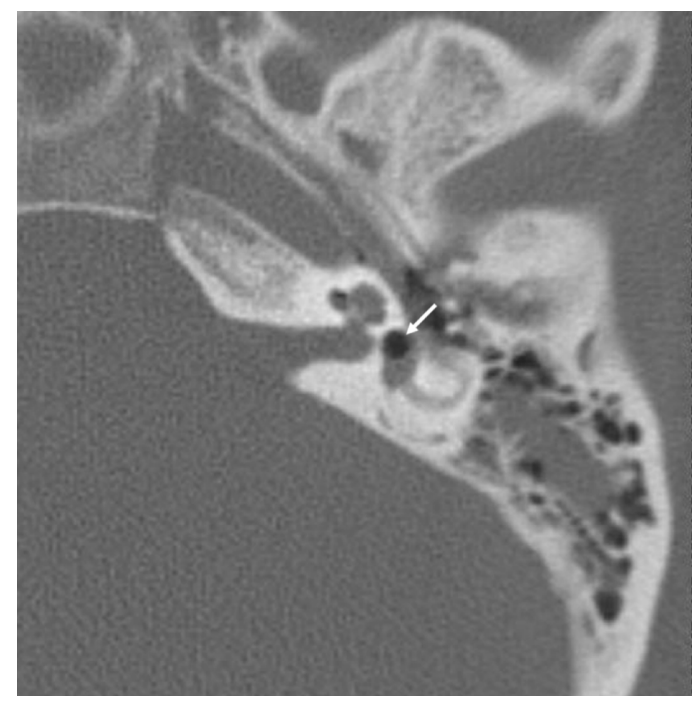

Figure 2 Axial computed tomography scan of the temporal bone showing air within the left vestibule (arrow).

lacerations in the anterior wall of the left external auditory canal and hemotympanum. A spontaneous nystagmus was also observed on the affected side. Pure-tone audiometry revealed a left-sided moderate to profound mixed hearing loss (Figure 1). Auditory brainstem responses, electrocochleography, and vestibular tests were not performed.

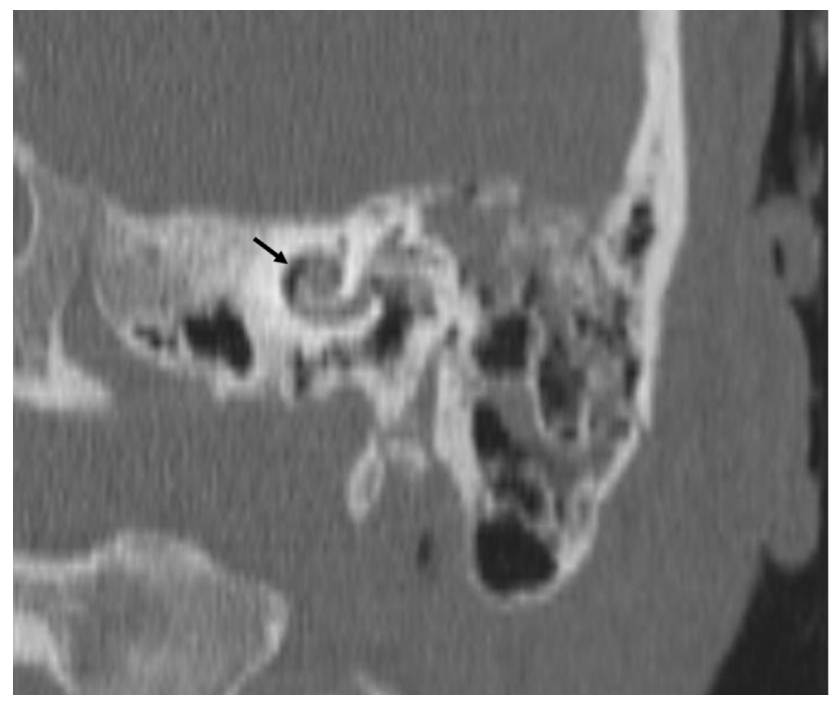

Figure 3 Coronal computed tomography scan of the temporal bone showing air within the basal turn of the cochlea (arrow).

A high-resolution CT scan of the temporal bones demonstrated the presence of a left-sided longitudinal temporal bone fracture without involvement of the otic capsule, with mild opacification of the middle ear cavity and mastoid air cells. No abnormalities of the ossicular chain were noted. Axial CT scan and reformatted two-dimensional images

\begin{tabular}{|c|c|c|c|c|c|c|}
\hline $\begin{array}{l}\text { Preoperative } \\
\text { PTA BC (dB) }\end{array}$ & Treatment & $\begin{array}{l}\text { Interval to } \\
\text { surgery (days) }\end{array}$ & $\begin{array}{l}\text { Postoperative } \\
\text { vestibular } \\
\text { symptoms }\end{array}$ & $\begin{array}{l}\text { Postoperative } \\
\text { auditory } \\
\text { symptoms }\end{array}$ & $\begin{array}{l}\text { Postoperative } \\
\text { PTA AC (dB) }\end{array}$ & $\begin{array}{l}\text { Postoperative } \\
\text { PTA BC (dB) }\end{array}$ \\
\hline 84 & Surgery & 6 & Resolved & Improved & 45 & NA \\
\hline 47 & Surgery & 26 & Resolved & Improved & 34 & 27 \\
\hline NA & Conservative & - & Resolved & NA & NA & NA \\
\hline NA & NA & NA & NA & NA & NA & NA \\
\hline 54 & Surgery & 7 & Resolved & Deteriorated & 103 & NA \\
\hline 37 & Surgery & 90 & NA & Deteriorated & NA & NA \\
\hline 70 & Surgery & 6 & Resolved & Improved & 68 & 31 \\
\hline NA & Conservative & - & NA & NA & NA & NA \\
\hline NA & Conservative & - & NA & Profound SNHL & NA & NA \\
\hline NA & Conservative & - & Resolved & Profound SNHL & NA & NA \\
\hline 67 & Conservative & - & Resolved & Stable & 110 & 67 \\
\hline NA & Conservative & - & Resolved & Fluctuating SNHL & 44 & 38 \\
\hline 10 & Conservative & - & Resolved & Improved & 68 & 27 \\
\hline NA & Surgery & 7 & Resolved & NA & NA & NA \\
\hline 55 & Surgery & 3 & Resolved & Improved & 48 & 40 \\
\hline
\end{tabular}


obtained along the long axis of the petrous bone (Poschl plane) detected small foci of air density within the left vestibule and the basal turn of the cochlea (Figures 2 and 3 ). These findings were consistent with pneumolabyrinth. The patient was placed on bed rest with intravenous corticosteroids and antibiotics. The patient continued to have severe vertigo with vomiting despite 3 days of conservative treatment and hence a transcanal exploratory tympanotomy was performed. The ossicular chain was intact and the stapes was in its normal position without evidence of subluxation into the vestibule. However, a small fracture placed anteriorly to the anterior crus of stapes was seen at the footplate. Perilymph was seen escaping from the oval window area through the fracture. Fluid leakage was not observed at the round window. The oval window was sealed with fat taken from the ear lobule. The vestibular symptoms disappeared immediately after the surgery, but hearing recovery was slow. At her last follow-up visit, 12 months after surgery, audiometry showed improvement in both air and bone conduction thresholds, especially at frequencies between 250 and 1,000 Hz (Figure 1).

\section{Discussion}

Pneumolabyrinth after temporal bone fracture is a rare phenomenon, and to date only 14 cases have been reported in the international literature. ${ }^{1,3-11}$ According to the compiled literature (Table 1), pneumolabyrinth secondary to temporal bone fracture occurs more frequently in men, with a male to female ratio of $14: 1$. The mean age at the time of trauma was $25(2-85)$ years. A transverse fracture of the temporal bone was detected in ten cases $(66.7 \%)$, a longitudinal fracture in three cases $(20 \%)$, and a mixed fracture in two cases (13.3\%). A vestibular pneumolabyrinth was found in ten cases (71.4\%) and a combined vestibular-cochlear pneumolabyrinth in the remaining four cases $(28.6 \%)$. There were no cases of isolated cochlear pneumolabyrinth, and details were unavailable in one case. The most common reported symptoms include hearing loss (100\%) followed by vertigo $(73 \%)$ and tinnitus (33\%).

High-resolution CT scan of the temporal bones with bone window in the axial and coronal planes is an extremely important tool for the diagnosis. The typical appearance of air inside the labyrinth is that of small black areas which can move within the inner ear space in response to changes in head position. Magnetic resonance imaging is not considered the technique of choice since neither air nor bone produce signals using this modality.
Due to the rarity of pneumolabyrinth, there has been no consensus regarding the management of the condition, which can be either conservative or surgical. In the literature, $50 \%$ of patients were treated surgically and $50 \%$ were treated conservatively. Conservative management includes bed rest, antibiotics, corticosteroids, and observation with serial CT scans. The aim of surgery is to close the connection between the inner ear and the air-filled middle ear spaces using fat, muscle, or fascia. In accordance with others, we believe that surgical exploration should be recommended for patients who show a progressive worsening of hearing function and/or persistent vestibular symptoms. ${ }^{1,8,10}$ Patients with perilymphatic fistulas persisting for $>7$ days are significantly more likely to develop meningitis and this should be another reason to intervene surgically. In the present case, we undertook surgical exploration because of the persistent and disabling vestibular symptoms and a suspected perilymphatic fistula.

Vestibular symptoms are usually relieved after treatment (either conservative or surgical). This is presumably because of vestibular compensation or elimination of the irritant air bubble secondary to absorption of air. In contrast, hearing outcomes are more varied. In fact, hearing may improve, deteriorate, or remain stable.

Presence of air within the cochlea has been reported to result in a more severe and irrecoverable sensorineural hearing loss. ${ }^{1}$ Kobayashi et al ${ }^{13,14}$ induced sensorineural hearing loss in animal models by introducing air bubbles into the labyrinth. They demonstrated that bubbles disturbed the propagation of the travelling wave of the basilar membrane. Further, the authors demonstrated that decreased cochlear function represented by cochlear potentials occurred after intrusion of air into the scala tympani, but was reversible when the air was expelled from the perilymph. In contrast, profound and irreversible hearing loss resulted after intrusion of air into the scala vestibule. They concluded that "it is possible that the prognosis is worse in cases with fistula of the oval window compared to that of the round window area, if the pneumolabyrinth is involved in the pathophysiology of perilymphatic fistula". In our patient, surgical repair resulted in immediate improvement of vestibular symptoms and a slow but progressive recovery of hearing. This is in contrast with the observation of Prisman et $\mathrm{al}^{1}$ who reported that surgical exploration and repair of perilymphatic fistula has been inconsistent in improving sensorineural hearing loss.

\section{Disclosure}

The authors report no conflicts of interest in this work. 


\section{References}

1. Prisman E, Ramsden JD, Blaser S, Papsin B. Traumatic perilymphatic fistula with pneumolabyrinth: diagnosis and management. Laryngoscope. 2011;121(4):856-859.

2. Lu YD, Zhang M, McCabe BF. Tube-perilymph fistula. An experimental study. Chin Med J (Engl). 1992;105(4):302-305.

3. Lipkin AF, Bryan RN, Jenkins HA. Pneumolabyrinth after temporal bone fracture: documentation by high-resolution CT. AJNR Am J Neuroradiol. 1985;6(2):294-295.

4. Yanagihara N, Nishioka I. Pneumolabyrinth in perilymphatic fistula: report of three cases. Am J Otol. 1987;8(4):313-318.

5. Nurre JW, Miller GW, Ball JB Jr. Pneumolabyrinth as a late sequela of temporal bone fracture. Am J Otol. 1988;9(6):489-493.

6. Weissman JL, Curtin HD. Pneumolabyrinth: a computed tomographic sign of temporal bone fracture. Am J Otolaryngol. 1992;13(2):113-114.

7. Lyos AT, Marsh MA, Jenkins HA, Coker NJ. Progressive hearing loss after transverse temporal bone fracture. Arch Otolaryngol Head Neck Surg. 1995;121(7):795-799.

8. Gross M, Ben-Yaakov A, Goldfarb A, Eliashar R. Pneumolabyrinth: an unusual finding in a temporal bone fracture. Int $J$ Pediatr Otorhinolaryngol. 2003;67(5):553-555.
9. Woodson EA, Smith RJH. Bilateral pneumolabyrinth diagnostic for otic capsule fractures without high resolution imaging. Otolaryngol Head Neck Surg. 2007;137(6):969-971.

10. de Negreiros J Jr, Sampaio AL, Sesana WE, Oliveira CA. Imaging case study of the month: traumatic pneumolabyrinth. Ann Otol Rhinol Laryngol. 2008;117(9):708-710.

11. Adil EA, Choudhary AK, Moser KW, Ghossaini SN. Vestibular pneumolabyrinth: why assessment with temporal bone computed tomography utilizing dynamic focal spot mode is important for the diagnosis. Emerg Radiol. 2011;18(1):43-45.

12. Mafee MF, Valvassori GE, Kumar A, Yannias DA, Marcus RE. Pneumolabyrinth: a new radiologic sign for fracture of the stapes footplate. Am J Otol. 1984;5(5):374-375.

13. Kobayashi T, Itoh Z, Sakurada T, Shiga N, Takasaka T. Effect of perilymphatic air perfusion on cochlear potentials. Acta Otolaryngol (Stockh). 1990;110(3-4):209-216.

14. Kobayashi T, Sakurada T, Ohyama K, Takasaka M. Inner ear injury caused by air intrusion to the scala vestibuli of the cochlea. Acta Otolaryngol (Stockh). 1993;113(6):725-730.
International Medical Case Reports Journal

\section{Publish your work in this journal}

The International Medical Case Reports Journal is an international, peer-reviewed open-access journal publishing original case reports from all medical specialties. Previously unpublished medical posters are also accepted relating to any area of clinical or preclinical science. Submissions should not normally exceed 2,000 words or

Submit your manuscript here: http://www.dovepress.com/international-medical-case-reports-journal-journal

\section{Dovepress}

4 published pages including figures, diagrams and references. The manuscript management system is completely online and includes a very quick and fair peer-review system, which is all easy to use. Visit http://www.dovepress.com/testimonials.php to read real quotes from published authors. 